\title{
O Retrato da Integração pela Via Normativa no Mercosul: Leis Para o Bloco ou para os Estados?
}

\author{
The Picture of Normative Integration Through Mercosur: \\ Laws to Block or to the States
}

Mayra Thaís Silva Andrade(*)

Resumo: O presente artigo tem por objetivo analisar a integração normativa do MERCOSUL. Investiga-se em que medida há possibilidade de se promover um Direito comum, sendo tal tarefa conjunta entre os órgãos integracionistas e seus Estados-membros. Pela pesquisa de dados oficiais dos Estados-membros, verificou-se que grande parte das normas emitidas pelos órgãos do bloco não são incorporadas aos ordenamentos jurídicos internos, ou sequer são votadas pelos Congressos Nacionais, refletindo um cenário de interesses internos. Conclui-se, que o MERCOSUL ainda não desenvolveu um sistema jurídico-normativo unificado; entretanto, pela atuação de seus órgãos, visando o compromisso de harmonização das legislações internas, há a possibilidade de formação de normas regionais em favor de se promover a segurança jurídica da sociedade mercosulina.

Palavras-chave: Integração normativa, Mercosul, segurança jurídica.

\begin{abstract}
This article aims to analyze the normative integration of MERCOSUR. Investigates to what extent there is a possibility to promote a common law, a task which is joint between the bodies integrationist and its Member States. Search by official data from Member States found that most of the rules issued by agencies of the block are not incorporated into domestic legal systems, or even are voted by the National Congress, reflecting a scene of domestic interests. It is concluded that MERCOSUR has not yet developed a unified legal system, legal, however, through the agency of their bodies, aimed committed to harmonization of domestic legislation, there is the possibility of formation of regional rules in favor of promoting safety MERCOSUR legal society.
\end{abstract}

Key words: Normative integration, Mercosur, legal safety.

(*) Pós-Graduanda em Estudos Diplomáticos pelo Centro de Direito Internacional (CEDIN), Belo Horizonte, Brasil. Recebido em 02.04.12 e aceito em 16.06.12. 


\section{INTRODUÇÃO}

As relações entre os indivíduos desenvolvem-se a partir de necessidades diversas, dentre elas o interesse de expandir ou proteger sua cultura ao longo das gerações. Com o surgimento da Nova Ordem Internacional em 1989, a globalização possibilitou a formação de redes de diálogos políticos, econômicos, comerciais, sociais e culturais entre Estados, instituições e indivíduos e, por conseguinte, a integração entre regiões internacionais.

Para regular e harmonizar as relações entre os Estados em cooperação tem-se a instituição do Direito de Integração Regional, contendo normas e princípios específicos, para estruturar a nova ordem internacional formada por Estados e blocos de integração regional, tendo como momento e formalidade máxima a união jurídico-política dos membros com a consolidação de um Direito Comunitário. Insta salientar que a referida integração é constituída por etapas, tendo início pela liberação comercial mediante a redução (com posterior eliminação) das tarifas protecionistas (Preferências Tarifárias e Livre Comércio) e evolui, paulatinamente, para o desenvolvimento de políticas macroeconômicas pela união comercial, econômica, jurídica e política (União Aduaneira e Mercado Comum), sendo constituídos órgãos que atuam junto aos interesses do bloco de maneira a criar direitos e obrigações aos seus tutelados (União econômica e monetária).

Dentre os esforços da integração de Estados, destaca-se a institucionalização do MERCOSUL no âmbito da América do Sul, bloco criado em 1991 para estreitar os laços políticos e econômicos, inicialmente, dos Estados: Brasil, Argentina, Paraguai e Uruguai.

O presente trabalho terá como tema de estudos o desenvolvimento da integração normativa no Mercado Comum do Sul (MERCOSUL), em específico, a atividade de incorporação das normas emitidas pelos órgãos do bloco nos ordenamentos jurídicos dos Estados-membros. Deste modo, propõe-se uma investigação sobre os pontos em que a União Aduaneira "imperfeita", no caso do MERCOSUL, conseguiu avançar nos últimos anos ao ponto de tornar possível a existência de um direito comum no bloco sul-americano.

\section{Breve Histórico do Direito Comunitário e a Integração Regional do Mercosul}

Em meados do século XX, após a Segunda Guerra Mundial, a Organização das Nações Unidas (ONU) foi criada e se mobilizou em favor dos direitos difusos ${ }^{(1)}$, que dizem respeito a toda coletividade numa tentativa de recuperar a dignidade da pessoa huma$\mathrm{na}^{(2)}$, que havia se desnorteado em meio aos conflitos étnico-culturais e, principalmente, político-econômicos do período das Guerras Mundiais. A partir de então, as relações internacionais se tornaram mais dinâmicas, favorecendo o debate e a integração, rede de

(1) Segundo Kildare Gonçalves Carvalho (2009), os direitos difusos são aqueles cujo exercício cabe a uma pluralidade de sujeitos, e não a cada indivíduo isoladamente.

(2) Explica Kildare Gonçalves Carvalho (2009) que a dignidade da pessoa humana é o valor do homem em sua dimensão de liberdade. 
Estados, proporcionando a criação de instrumentos normativos e valores comuns entre os acordantes, como forma de superação das adversidades socioeconômicas (SOARES, 1995) como o Direito de Integração Regional e o Comunitário.

Sobre o início do Direito Comunitário oriundo da Europa, percebe-se o sentimento de união de seus governos em prol da reconstrução do continente que estava alastrado em virtude das consequências catastróficas que se seguiram no período das duas Grandes Guerras Mundiais, o que culminou na unificação institucional da União Europeia em seus aspectos políticos, econômicos, sociais e culturais, o que viabilizou o avanço da integração e reforçar a segurança jurídica.

Fora do contexto territorial europeu, mas no mesmo sentimento de integração dos povos em circunstâncias de conflitos governamentais, tem-se a figura de Simón Bolívar, líder do movimento separatista das colônias espanholas de sua metrópole Europeia. Em 1815, Simón Bolívar escreveu a "Carta da Jamaica" em que estavam presentes seus desejos de liberdade latino-americana perante o domínio sofrido no sistema colonial, como expõe Soares (1997, p. 71): “(...) e o 'libertador' manifestou os referidos anseios no Congresso Anfictiônico do Panamá, instalado em 22 de junho de 1826."

Apesar de não ter prosperado o ideal de Bolívar em promover uma integração Latino-americana, o progresso integracionista se desenvolveu e, nesse sentido, criou-se o Mercado Comum do Sul (MERCOSUL), instituído em 26 de março de 1991, quando Argentina, Brasil, Paraguai e Uruguai tornaram-se signatários do Tratado de Assunção $(\mathrm{TA})^{(3)}$. O sistema do bloco foi fundamentado para promover a integração econômica mercantil. Entretanto, pela dinâmica dos aspectos políticos, econômicos e sociais da globalização, diversos assuntos foram acrescentados à agenda do bloco, sendo passíveis de regulamentação para uma maior integração.

Os Estados-membros do MERCOSUL possuem significativa influência e força por sua integração regional, observadas e ressalvadas as dificuldades econômicas e a desigualdade social percebida, pois aqueles se enquadram nos aspectos caracterizadores de Estados em desenvolvimento (antes nomeados de $3^{\circ}$ Mundo). Conforme Silva (1995, p. 235) afirma: “(...) o Tratado de Assunção está imbuído de uma visão neoliberal de integração, onde a criação de comércio e a especialização são metas principais para o processo [da retomada do crescimento e desenvolvimento econômico da região]."

Os atuais órgãos de integração regional do MERCOSUL são: Conselho do Mercado Comum (CMC); Grupo Mercado Comum (GMC); Comissão de Comércio do MERCOSUL (CCM); Foro Consultivo Econômico-Social (FCES); Secretaria Administrativa do MERCOSUL (SAM); e o atual Parlamento do MERCOSUL (PARLASUL), que substituiu a Comissão Parlamentar Conjunta (CPC), criado em 06 de dezembro de 2006; Tribunais Ad Hoc; e o Tribunal Permanente de Revisão (TPR), constituído pelo Protocolo de Olivos em 18 de fevereiro de 2002, competente para julgar recursos de revisão advindos de um tribunal Ad Hoc.

(3) Posteriormente, uniram-se ao MERCOSUl os Estados: Chile, Bolívia, Peru, Colômbia, Equador e Venezuela. 
A maior parte dos Estados-membros do MERCOSUL expressou em suas Constituições a importância da integração regional sul-americana e outros, como Argentina e Paraguai, ainda reconhece a possibilidade de criação de órgãos supranacionais. Sobre este aspecto, discorre Andrade (2011, p. 08):

(...) é importante que haja o reconhecimento e aprovação da integração pelo ordenamento jurídico interno dos Estados integrantes do MERCOSUL, de outra maneira tal união seria infrutífera e ineficaz para a evolução das negociações extrabloco e dos direitos e garantias conferidos aos seus destinatários.

Conforme as disposições sobre os órgãos do bloco trazidas no Protocolo de Ouro Preto (assinado em 1994), os órgãos do MERCOSUL possuem natureza intergovernamental. Assim, àqueles não foi concedida competência superior aos Estados, mas sim atuam em conjunto aos Poderes Nacionais como o Legislativo, o Executivo e o Judiciário, para promoverem a aproximação entre o direito de integração existente no MERCOSUL e o interno dos Estados, para que obtenham êxito na atuação internacional.

As normas emanadas pelo MERCOSUL estão dispostas no artigo 41 do Protocolo de Ouro Preto. O Direito de Integração primário trata-se do Tratado de Assunção, seus protocolos e instrumentos adicionais ou complementares; e os acordos celebrados no âmbito do Tratado de Assunção e seus protocolos. Como Direito de Integração secundário, têm-se as Decisões do CMC, as Resoluções do GMC e as Diretrizes da CCM, adotadas desde a entrada em vigor do TA. Para somar a essas fontes do direito do MERCOSUL, consideram-se também as jurisprudências dos Tribunais arbitrais e do TPR que fazem lei entre as partes.

No que tange ao desenvolvimento do Direito do MERCOSUL, os estudiosos do tema possuem entendimentos divergentes.

Segundo Andrade (2011, p. 12-13):

O Direito Comunitário no bloco ainda não foi concretizado em seu caráter amplo, pois a união monetária, político-econômica e, principalmente, cultural são questões de sucessivas discussões políticas que possivelmente apenas se concretizam conforme os interesses dos Estados-membros, visto que ao mesmo tempo em que se pretende potencializar o bloco, cada Estado possui suas próprias dificuldades estruturais de caráter político, econômico e social, que muitas das vezes retardam o desenvolvimento do MERCOSUL.

Parte da doutrina afirma que a integração mercosulina está "presa" às decisões políticas do bloco e que, assim, não há uma integração efetiva entre os Estados-membros do MERCOSUL pela falta de interesse regional e prevalência do interno (EVERTS, 1998). Seguem tal argumento: Guerra (2009), Everts (1998), Almeida (1999) e Ferreira (2009).

O entendimento de autores, como Costa e Silva (2003), Anselmo (2000), Silva; Silva (2003), dispõe que para existir um Direito comum ao MERCOSUL é necessário haver o consenso entre o poder nacional e as competências comunitárias, não se trata de uma renúncia à soberania e sim uma transferência de prerrogativas inerentes às jurisdições nacionais para os órgãos de integração regional. 
Conforme Ventura (1995), deveria haver um órgão jurisdicional supranacional mercosulino para garantir a eficácia de suas decisões. Seguem esse entendimento autores como: Silva; Silva (2003), Magalhães (2000) e Ventura (1995).

Sobre a aplicabilidade direta das normas do MERCOSUL, parcela dos autores afirma que não há tal efetivação, pois grande parte das decisões do CMC e do GMC exige ratificação pelo ordenamento interno dos Estados-membros (VENTURA, 1995; CARNEIRO, 2007; VIEIRA; CHIAPPINI, 2008).

Em que pese o procedimento de integração das normas mercosulinas pelo direito interno ser uma constante no MERCOSUL, aquele não é uma exigência, vez que o artigo 42 do POP dispõe que o procedimento de incorporação será feito quando necessário pelos Estados.

Percebe-se, assim, que a partir da publicação de uma decisão, parecer ou jurisprudência apresentada pelos órgãos mercosulinos, pode haver uma possibilidade dos Estados e da sociedade, além de ter conhecimento das normas do bloco, delas se utilizarem em defesa de seus direitos conferidos por aquela instituição integracionista.

Coaduna-se a esse entendimento o que dispõe Perotti (2002) ao afirmar que as normas do MERCOSUL possuem aplicabilidade imediata vez que não há a exigência expressa nos Tratados do bloco da obrigatoriedade de incorporação daquelas, e que, no caso de dúvidas sobre sua aplicação, àquelas deve-se recorrer de forma imediata para conferir segurança jurídica aos tutelados mercosulinos.

No mesmo sentido, tem-se buscado entendimento sobre a possibilidade dos órgãos mercosulinos formarem um ordenamento comum ao bloco pelas suas atuações em âmbito regional, pois, conforme ressaltado por Carneiro (2007, p. 128):

(...) o que importa é o fato de termos, ou não, instituições comunitárias que garantam a concretização desses princípios gerais [do Direito Comunitário]. Ou seja, é preciso auferir se as instituições mercosulinas têm sido capazes de exercer controle eficaz sobre a aplicação do direito gerado no bloco regional.

No mesmo sentido, afirma Carvalho (2006, p. 20):

Não há uma relação direta a priori entre instituições supranacionais e efetividade. Por si só, a introdução, no arcabouç̧o jurídico institucional de um processo de integração, de elementos tradicionalmente associados ao conceito de supranacionalidade não assegura a consecução dos objetivos atribuídos à organização ou o adequado cumprimento das decisões adotadas nesse âmbito. Por outro lado, nada impede que, na ausência desses elementos, as instituições possam criar uma efetiva integração entre seus membros e gerar, naturalmente, uma demanda por maior integração, graças à capacidade de defesa e promoção dos interesses de seus integrantes.

Outros autores têm destacado que as referidas atribuições dos órgãos mercosulinos possibilitam a formação de um ordenamento jurídico comum, desenvolvendo uma segurança jurídica e harmonização nas relações políticas e econômicas dos integrantes 
do bloco. Sobre a atuação do TPR, afirma Strenger (2009, p.193) que "apesar de ser um órgão de caráter intergovernamental, possui traços de supranacionalidade, isto porque suas decisões são dotadas de caráter obrigatório, sendo sua imperatividade independente da vontade individual dos Estados-membros".

Coaduna-se com o referido entendimento, Ribeiro (2008) sobre o Parlasul. Afirma que, além de órgão representativo dos cidadãos do MERCOSUL, o Parlasul está em processo de formação para ter o caráter de um órgão supranacional, proposta já feita em 2000 na disposição n. 35(4) da extinta Comissão Parlamentar Conjunta. No plano comunitário, as funções legislativas daquele órgão poderão ser aplicadas diretamente ao direito interno dos Estados-membros garantindo direitos e obrigações aos seus destinatários (RIBEIRO, 2008).

\section{A Aplicação Interna das Normas Emanadas dos Ógãos do Mercosul}

No que se refere aos aspectos normativos, um ordenamento jurídico comum é o que confere segurança jurídica e estabilidade nas relações políticas, econômicas e sociais entre os destinatários do bloco comunitário.

As normas emanadas pelos órgãos do bloco são obrigatórias para os Estados-membros e, conforme o artigo 42 do POP, essas normas deverão ser incorporadas aos ordenamentos jurídicos internos, quando necessário, pelos procedimentos previstos na legislação de cada Estado.

Assim, tem-se no artigo 40 do POP o procedimento que deveria ser adotado pelos Estados-membros para a vigência simultânea das normas do MERCOSUL; deveria, pois é cediço que os países possuem seus próprios procedimentos de internalização das normas, sendo esses reconhecidos pelo artigo 42 do POP.

O procedimento do artigo 40 do POP (MAZUOLLI, 2009) resume-se em: a) aprovada a norma, os Estados-membros adotarão as medidas necessárias para a sua incorporação ao ordenamento jurídico nacional e comunicarão as mesmas à Secretaria Administrativa do MERCOSUL; b) informada a Secretaria Administrativa do MERCOSUL sobre as incorporações aos respectivos ordenamentos jurídicos, aquela comunicará o fato a cada Estado-membro; c) a norma entrará em vigor simultaneamente nos Estados-membros 30 dias após a data da comunicação feita pela SAM. Assim, os Estados farão publicidade, por seus Diários Oficiais, no referido prazo, do início da vigência da norma incorporada.

Cabe ressaltar que não são todas as normas emanadas pelo MERCOSUL que necessitam ser incorporadas, pois, conforme o que dispôs a Decisão n. 23 de 2000 do CMC $^{(5)}$, dispensa-se a incorporação quando os Estados-membros entenderem, conjuntamente, que o conteúdo da norma tratam de assuntos relacionados ao funcionamento interno do bloco, ou quando o conteúdo da norma já estiver contemplado no ordenamento jurídico interno do Estado.

(4) Disposição CPC n. 35/00. Emanada da Comissão Parlamentar Conjunta. Porto Alegre, 09 de novembro de 2000.

(5) Decisão n. 23/2000 do CMC. Disponível em: <http://www.mercosur.int/innovaportal/v/3189/1/secretaria/ decisiones_2000> Acesso em: 20 set. 2011. 
Dessa forma, com o objetivo de analisar a dinâmica hodierna normativa do MERCOSUL, investigou-se no presente trabalho, a incorporação das normas de 2008 a 2010, sendo a escolha deste biênio relacionada aos recentes esforços de cooperação formalizados entre os Estados para se consolidar as obrigações e as garantias dos cidadãos mercosulinos.

Assim, com base nos Diários Oficiais de publicação legislativa dos Estados, bem como da Cartilha do Cidadão do MERCOSUL de 2010, obteve-se os seguintes resultados:

a) Argentina: n. 12/08 sobre o Programa de Integração Produtiva do MERCOSUL ${ }^{(6)}$; conjuntamente as de n. 13/08 sobre a criação do Fundo MERCOSUL de apoio às Pequenas e Médias empresas envolvidas em iniciativas de integração produtiva, a n. 43/08 sobre a constituição da Comissão Assessora para a Implementação do Fundo MERCOSUL de Garantias para Micro, Pequenas e Médias Empresas e, a Decisão n. 13/09 que aprova a subscrição do "Acordo de Sede entre a República Oriental do Uruguai e o MERCOSUL para o funcionamento da Secretaria Permanente do Foro Consultivo Econômico-Social (FCES)" (7); n. 18/09, sobre a lista dos produtos e exceções à Tarifa Externa Comum do MERCOSUL ${ }^{(8)}$; n. 30/08 para o Fundo para a Convergência Estrutural do MERCOSUL (FOCEM) receber contribuições voluntárias adicionais dos Estados-partes e n. 33/08 que aprova a arte do Selo MERCOSUL Cultural ${ }^{(9)}$; n. 53/08 sobre o Regime Aduaneiro de Bagagem no MERCOSUL ${ }^{(10)}$; n. 25/09 sobre modificação da Tarifa Externa Comum (TEC) ${ }^{(11)}$; n. 28/09 para que a República Argentina e a República Federativa do Brasil possam manter em suas listas nacionais de exceções à Tarifa Externa Comum até 100 itens tarifários até 31 de dezembro de 2011 ${ }^{(12)}$; n. 30/10 sobre a aprovação das "Diretrizes para a celebração de um Acordo de Investimentos no MERCOSUL" até a Decisão n. 67/10 sobre a remessa do documento "Eixos, Diretrizes e Objetivos Prioritários do Plano Estratégico de Ação Social do MERCOSUL (PEAS)" às Reuniões de Ministros e Reuniões Especializadas responsáveis pelos temas sociais ${ }^{(13)}$; n. 31/10, sobre a elaboração e divulgação das demonstrações financeiras ${ }^{(14)}$; e n. 19/10 sobre o hasteamento da bandeira do MERCOSUL ${ }^{(15)}$.

(6) Disponível em: <http://www.boletinoficial.gov.ar/DisplayPdf.aspx?s=BPBCF\&f=20101130>Acesso em: 20 set. 2011.

(7) Disponível em: <http://www.boletinoficial.gov.ar/DisplayPdf.aspx?s=BPBCF\&f=20100805>Acesso em: 20 set. 2011.

(8) Pelo Decreto n. 1851/2011. Disponível em: <http://www.boletinoficial.gov.ar/DisplayPdf.aspx?s=BPBCF\&f=20111117> Acesso em: 20 set. 2011.

(9) Pela Resolução 590/2010 da Secretaria de Cultura. Disponível em: <http://www.boletinoficial.gov.ar/DisplayPdf. aspx?s=BPBCF\&f=20100317> Acesso em: 20 set. 2011.

(10) Pela Resolução n. 2731 da Administração Federal de Aduanas. Disponível em: <http://www.boletinoficial.gov.ar/ DisplayPdf.aspx?s=BPBCF\&f=20091222> Acesso em: 20 set. 2011.

(11) Disponível em: <http://www.boletinoficial.gov.ar/DisplayPdf.aspx?s=BPBCF\&f=20100928>Acesso em: 20 set. 2011.

(12) Disponível em: <http://www.boletinoficial.gov.ar/DisplayPdf.aspx?s=BPBCF\&f=20101006>Acesso em: 20 set. 2011.

(13) Disponível em: <http://www.boletinoficial.gov.ar/DisplayPdf.aspx?s=BPBCF\&f=20110428>Acesso em: 20 set. 2011.

(14) Pela Resolução n. 585/2011 da Comissão Nacional de Valores. Disponível em: <http://www.boletinoficial.gov.ar/Inicio/ Index.castle> Acesso em: 20 set. 2011.

(15) Pelo Decreto n. 88/2011. Disponível em: <http://www.boletinoficial.gov.ar/Inicio/Index.castle> Acesso em: 21 set. 2011. 
b) Brasil: as Decisões n. 01/08 sobre a aprovação das normas sobre a "Especificação de Características Técnicas da Infraestrutura Informática para o Intercâmbio Eletrônico de Informações de Operações Aduaneiras através do Sistema de Intercâmbio de Informação de Registros Aduaneiros - INDIRA" e n. 53/08 que aprova o "Regime Aduaneiro de Bagagem no MERCOSUL" (16); n. 31/10 sobre a aprovação da "Regulamentação Mínima do Mercado de Valores sobre a elaboração e divulgação das demonstrações financeiras", para operações celebradas no âmbito do MERCOSUL com valores negociáveis de sociedades com oferta pública autorizada pelos Estados-membros ${ }^{(17)}$; n. 17/08 que aprova o texto do Acordo sobre a Criação e a Implementação de um Sistema de Credenciamento de Cursos de Graduação para o Reconhecimento Regional da Qualidade Acadêmica dos Respectivos Diplomas no MERCOSUl e Estados Associados, adotado em San Miguel de Tucumán, em 30 de junho de 2008(18); n. 33/08 que aprova a arte do Selo MERCOSUL Cultural e da outras providências ${ }^{(19)}$; n. 58/08 que prorrogou mais uma vez o início da vigência do Regime Comum de Bens de Capital e bens de informática e de telecomunicações não Fabricados no MERCOSUL, para Iำ de janeiro de 2011, os ex-tarifários simples e Sistemas Integrados de Bens de Informática e Telecomunicações (BIT), com as alíquotas ad valorem do Imposto de Importação reduzidas para 2\% (dois por cento) ${ }^{(20)}$; n. 11/09 que estabelece condições específicas que facilitam a utilização dos recursos do FOCEM para o financiamento de projetos de integração produtiva pelo Brasil ${ }^{(21)}$; n. 28/09 sobre acréscimos à lista de exceções à Tarifa Externa Comum (TEC), alterando a Nomenclatura Comum do MERCOSUL e as alíquotas do Imposto de Importação que compõem a TEC ${ }^{(22)}$; e n. 01/10 sobre o Regulamento do Fundo para a Convergência Estrutural do MERCOSUL ${ }^{(23)}$.

(16) Pelo Decreto do Executivo n. 6870. Disponível em: <http://www.planalto.gov.br/ccivil_03/_Ato2007-2010/2009/ Decreto/D6870.htm> Acesso em: 21 set. 2011.

(17) Pela Deliberação n. 659 da Comissão de Valores Mobiliários (CVM). Disponível em: <http://www.cvm.gov.br/port/ infos/Comunicado\%20659.asp> Acesso em: 21 set. 2011.

(18) Pelo Decreto Legislativo n. 131/2011. Disponível em: <http://www2.camara.gov.br/legin/fed/decleg/2011/ decretolegislativo-131-26-maio-2011-610674-publicacaooriginal-132609-cn.html> Acesso em: 21 set. 2011.

(19) Pela Portaria MINC n. 70/2009 do Ministro de Estado da Cultura. Disponível em: <http://www.jurisite.com.br/portaria/ portarias/por554.html> Acesso em: 21 set. 2011

(20) Pela Resolução n. 81/2008 do Presidente do Conselho de Ministros da Câmara de Comércio Exterior. Ea mesma Decisão n. 58/08 CMC foi aprovada novamente pela Resolução n. 82/2008 do Presidente do Conselho de Ministros da Câmara de Comércio Exterior. Disponível em: <http://www.in.gov.br/imprensa/visualiza/index.jsp?jornal=1\&pagina=19\& data=19/12/2008> e <http://www.in.gov.br/imprensa/visualiza/index.jsp?.jornal=1\&pagina=20\&data=19/12/2008> Acesso em: 21 set. 2011.

(21) Pelo Decreto do Executivo n. 7.150, de 08 de abril de 2010. Disponível em: <http://www.planalto.gov.br/ccivil_03/_ Ato2007-2010/2010/Decreto/D7150.htm> Acesso em: 21 set. 2011.

(22) A nomenclatura comum do MERCOSUL refere-se aos códigos das mercadorias relacionadas para as transações pela Tarifa Externa Comum. Tal Decisão do CMC foi incorporada pela Resolução n. 47/2010 do Presidente do Conselho de Ministros da Câmara de Comércio Exterior — CAMEX. Disponível em: <http://www.in.gov.br/imprensa/visualiza/ index.jsp?jornal=1\&pagina $=15 \&$ data $=25 / 06 / 2010>$ Acesso em: 21 set. 2011.

(23) Pelo Decreto do Executivo n. 7.362, de 22 de novembro de 2010. Disponível em: <https://www.planalto.gov.br/ ccivil_03/_ato2007-2010/2010/decreto/d7362.htm> Acesso em 23 set. 2011. 
c) Paraguai: Decisões n. 28/09 sobre acréscimos à lista de exceções à Tarifa Externa Comum (TEC), alterando a Nomenclatura Comum do MERCOSUL e as alíquotas do Imposto de Importação que compõem a TEC ${ }^{(24)}$; n. 57 sobre a revisão do Regime Comum de Importação de bens de capital não produzidos no MERCOSUL; e a n. 58/10 sobre as listas nacionais de exceções à TEC ${ }^{(25)}$.

d) Uruguai: Decisões n. 59/08 que substitui o artigo 11 do Anexo da Decisão CMC n. 34/03 pelo seguinte: "Artigo 11 - A partir de 1ㅇ de janeiro de 2013 apenas serão admitidas importações, com os benefícios previstos no presente regime, de bens de capital novos, suas partes, peças e componentes, classificados nos códigos identificados como "BK" na Nomenclatura Comum do MERCOSUL, não produzidos que constem da Lista Comum"(26); n. 1/09 sobre o Regime de Origem do MERCOSUL ${ }^{(27)}$; n. 17/09 declara que os níveis de TEC superiores aos níveis consolidados na OMC; n. 18/09 sobre a suspensão de condições da TEC ${ }^{(28)}$; n. 20/09 sobre os Regimes Especiais de Importação ${ }^{(29)}$; n. 25/09 sobre a modificação da TEC ${ }^{(30)}$; n. 44/10 sobre o Regime de Origem do MERCOSUL ${ }^{(31)}$; n. 56/10 sobre o Programa de Consolidação da União Aduaneira; n. 59/10 sobre a proposta de tratamento a ser dado aos regimes especiais de importação adotados unilateralmente pelos Estados-partes, que impliquem a isenção total ou parcial dos direitos aduaneiros (Tarifa Externa Comum)(32); n. 63/10 sobre a criação do Alto Representante Geral do MERCOSUL como órgão do Conselho do Mercado Comum (CMC) ${ }^{(33)}$.

Cabe ressaltar que Argentina, Brasil, Paraguai e Uruguai incorporaram as seguintes Decisões do CMC: n. 40/08 aprovação do Sub-standart - 3.7.19 com os requisitos

(24) Pelo Decreto n. 5.814/2010. Disponível em: <http://www.presidencia.gov.py/v1/wp-content/uploads/2011/11/ decreto76721.pdf> Acesso em: 23 set. 2011.

(25) Pelo Decreto n. 8.103/2011 do Ministério da Fazenda. Disponível em: <http://www.presidencia.gov.py/vl/wp-content/ uploads/2011/12/decreto81031.pdf> Acesso em: 21 set. 2011.

(26) Pelo Decreto n. 4.97/2011. Disponível em: <http://www.aduanas.gub.uy/innovaportal/v/9170/3/innova.front/ decreto_n\%C2\%B0_497_011.html>Acesso em: 22 set. 2011.

(27) Pelo Decreto n. 169/2011 que aprovou o 77 Protocolo Adicional ao Acordo de Complementação Econômica n. 18. Disponível em:<http://www.aduanas.gub.uy/innovaportal/v/8180/1/innova.front/decreto_n ${ }^{\circ}$ 169_011.html>Acesso em: 20 set. 2011.

(28) Pelo Decreto n. 74/2010. Disponível em: <http://www.aduanas.gub.uy/innovaportal/v/6121/1/innova.front/decreto_ n _74_010.html> Acesso em: 19 set. 2011.

(29) Pelo Ministério das Relações Exteriores — Questão n. 672/2011. Disponível em: <http://archivo.presidencia.gub.uy/ sci/decretos/2011/12/mrree_672.pdf> Acesso em: 19 set. 2011.

(30) Pelo Decreton. 62/2010. Disponível em: $<$ http://www.aduanas.gub.uy/innovaportal/v/6693/1/innova.front/decreto_n ${ }^{\circ}$ 62_010.html> Acesso em: 21 set. 2011.

(31) Pelo Decreto n. 504/2011 que aprovou o 86ํㅜ Protocolo Adicional ao Acordo de Complementação Econômica n. 18. Disponível em: <http://www.aduanas.gub.uy/innovaportal/v/9281/1/innova.front/decreto_nº504_011.html>Acesso em: 15 ago. 2011.

(32) Pelo Decreto n. 503/2011 do Ministério das Relações Exteriores. Disponível em: <http://www.impo.com.uy/copetes/ pdf/20120125/indice.pdf> Acesso em: 15 ago. 2011

(33) Pelo Decreto n. 339/2011 do Ministério das Relações Exteriores. Disponível em: <http://www.impo.com.uy/copetes/ pdf/20111005/indice.pdf> Acesso em: 15 ago. 2011. 
fitossanitários para vegetais vitis vinifera (videira) a serem aplicados no intercâmbio comercial entre os Estados-membros e a n. 57/08 sobre a modificação da Nomenclatura Comum do MERCOSUL e sua a TEC ambas do CMC ao Acordo de Complementação Econômica n. 18 ${ }^{(34)}$.

Salienta-se, ainda, que, conforme a Cartilha do Cidadão do MERCOSUL de 2010, todos os Estados-membros mantêm vigentes nos ordenamentos jurídicos internos as seguintes Decisões do CMC: n. 12/08 formulário de solicitação de avaliação de tecnologias em saúde; n. 15/08 diretrizes para o estabelecimento do marco regulatório do setor postal no MERCOSUL; n. 18/08 sobre convênio de financiamento junto à União Europeia para o projeto "Apoio à sociedade da informação do MERCOSUL"; n. 09/09 aprovação do Sub-standart - 3.7.2 com os requisitos fitossanitários para allium sativum (alho) a serem aplicados no intercâmbio comercial entre os Estados-membros e n. 14/09 aprovação do Sub-standart - 3.7.11 com os requisitos fitossanitários para Lotus SPP (lótus) a serem aplicados no intercâmbio comercial entre os Estados-membros ${ }^{(35)}$.

Como resultado, tem-se que foram emitidas 59 Decisões do CMC em 2008 e, apenas, 14 foram incorporadas pelos Estados-membros; das 33 Decisões emitidas em 2009, apenas 11 foram incorporadas; das 67 Decisões emitidas em 2010, apenas 39 foram incorporadas.

Sobre as Resoluções emitidas no período de 2008 a 2010 pelo GMC que foram incorporadas pelos seguintes Estados integrantes do MERCOSUL, tem-se:

a) Argentina: n. 64/08 sobre o uso de faixas refletivas em veículos de transporte rodoviário de cargas ou passageiros ${ }^{(36)}$; n. 68/08 sobre as normas gerais relativas aos funcionários da Secretaria do MERCOSUL, da Unidade Técnica FOCEM e da Secretaria do Tribunal Permanente de Revisão ${ }^{(37)}$; n. 24/09 sobre a revogação das Resoluções nos 26/95 e 07/99 sobre os procedimentos de vigilância epidemiológica e sanitária em meios de transporte e áreas de portos, aeroportos, terminais e pontos de fronteiras no MERCOSUL com relação à síndrome respiratória aguda grave $^{(38)}$; n. 32/09 para estabelecer um modelo único do certificado de inspeção técnica veicular para todos os tipos de veículos de transporte por rodovias do MERCOSUL; n. 38/09 sobre a lista de substâncias corantes permitidas para produtos de higiene pessoal, cosméticos e perfumes ${ }^{(39)}$; n. 20/10 periodicidade da

(34) Disponível em: <http://www.boletinoficial.gov.ar/DisplayPdf.aspx?s=BPBCF\&f=20120110>Acesso em: 10 out. 2011.

(35) Disponível em: <http://www.mercosur.int/innovaportal/file/2432/1/cartilla_ciudadano_por.pdf>Acesso em: 10 out. 2011.

(36) Pela Resolução n. 59/2011 da Secretaria de Transporte. Disponível em: <http://www.boletinoficial.gov.ar/DisplayPdf. aspx?s=BPBCF\&f=20110405> Acesso em: 10 out. 2011.

(37) Pela Resolução n. 59/2011 da Secretaria de Transporte. Disponível em: <http://www.boletinoficial.gov.ar/DisplayPdf. aspx?s=BPBCF\&f=20110405> Acesso em: 10 out. 2011.

(38) Pela Disposição n. 2.160/2011 do Ministério da Saúde (Obs.: Esta Resolução necessita ser incorporada apenas ao ordenamento jurídico interno da República Argentina, da República Federativa do Brasil e da República Oriental do Uruguai) que revogou a Resolução n. 48/2002 do GMC sobre "Regulamento Técnico MERCOSUL sobre Lista de Substâncias que os Produtos de Higiene Pessoal, Cosméticos e Perfumes não devem conter, exceto nas condições e com as Restrições Estabelecidas. Disponível em: <http://www.boletinoficial.gov.ar/DisplayPdf.aspx?s=BPBCF\&f=20110405> Acesso em: 10 out. 2011.

(39) Pela a Disposição n. 2.162/2011 do Ministério da Saúde. Disponível em: <http://www.boletinoficial.gov.ar/DisplayPdf. aspx?s=BPBCF $\& \mathrm{f}=20110405>$ Acesso em: 10 out. 2011. 
atualização no MERCOSUL das listas e intercâmbio de informação sobre substâncias psicotrópicas, entorpecentes, precursoras e sujeitas a controle especial ${ }^{(40)}$; n $\underline{\text { os }}$ 29/10 e 30/10 sobre a modificação da Nomenclatura Comum do MERCOSUL e sua correspondente $\mathrm{TEC}^{(41)}$; n. 39/10 sobre ordenadores de pagamento e modificação da estrutura organizacional da Secretaria do Tribunal Permanente de Revisão; n. 46/10 sobre o Regulamento Técnico MERCOSUL sobre lista de substâncias que os produtos de higiene pessoal, cosméticos e perfumes não devem conter exceto nas condições e com as restrições estabelecidas; n. 47/10 sobre a modificação da Nomenclatura Comum do MERCOSUL e sua correspondente TEC; n. 48/10 sobre a lista de substâncias de uso cosmético ${ }^{(42)}$; n. 49/10 sobre a estrutura da unidade técnica do FOCEM; n. 50/10 sobre ordenadores de despesas da Secretaria do Tribunal Permanente de Revisão; n. 51/10 sobre a designação dos membros do Tribunal Administrativo-laboral do MERCOSUL; n. 52/10 sobre especificações do modelo único do certificado de inspeção técnica veicular; $n$. 53/10 sobre alteração nos requisitos zoosanitários para a importação de equídeos destinados aos estados partes do MERCOSUL; n. 54/10 sobre o funcionamento e estrutura salarial dos órgãos do MERCOSUL; n. 55/10 sobre o orçamento da Secretaria do MERCOSUL para 2011; n. 56/10 sobre o orçamento da secretaria do tribunal permanente de revisão para 2011; n. 57/10 sobre o convênio de financiamento entre o MERCOSUL e União Europeia no projeto "Apoio à sociedade da informação do MERCOSUL"; n. 58/10 sobre a modificação da Nomenclatura Comum do MERCOSUL e sua correspondente TEC.

b) Brasil: n. 10/08 sobre o Regulamento Técnico para a fabricação de preservativos masculinos de látex de borracha natural ${ }^{(43)}$; n. 27/08 sobre o orçamento da Secretaria do Tribunal Permanente de Revisão de julho a dezembro de $2008^{(44)}$; n. 38/09 sobre lista de substâncias corantes permitidas para produtos de higiene pessoal, cosméticos e perfumes ${ }^{(45)}$.

c) Paraguai: n. 58/10 sobre a modificação da Nomenclatura Comum do MERCOSUL e sua correspondente TEC ${ }^{(46)}$.

(40) Disponível em: <http://www.boletinoficial.gov.ar/DisplayPdf.aspx?s=BPBCF\&f=20100928>Acesso em: 10 out. 2011.

(41) Pela Resolução n. 47/2010 do Presidente do Conselho de Ministros da Câmara de Comércio Exterior — CAMEX. Disponível em: <http://www.in.gov.br/imprensa/visualiza/index.jsp?jornal=1\&pagina $=15 \&$ data $=25 / 06 / 2010>$ Acesso em: 25 set. 2011.

(42) Disponível em: <http://www.boletinoficial.gov.ar/DisplayPdf.aspx?s=BPBCF\&f=20110420>Acesso em: 10 out. 2011.

(43) Pela Resolução da Diretoria Colegiada n. 62/2009 da Anvisa. Disponível em: <http://www.in.gov.br/imprensa/visualiza/ index.jsp?jornal=1 \&pagina $=56 \&$ data=24/06/2009> Acesso em: 10 out. 2011.

(44) Pelo Decreto n. 6.616, de 23 de outubro de 2008 pelo Brasil. Disponível em: < http://www.planalto.gov.br/ccivil_03/_ Ato2007-2010/2008/Decreto/D6616.htm> Acesso em 25 set. 2011.

(45) Pela Resolução da Diretoria Colegiada n. 39, de 30 de agosto de 2010. Disponível em: <ftp://ftp.saude.sp.gov.br/ftpsessp/ bibliote/informe_eletronico/2010/iels.set.10/Iels167/U_RS-MS-ANVISA-RDC-39_300810.pdf>Acesso em: 10 out. 2011.

(46) Pelo Decreton. 7.672. Disponível em:<http://www.presidencia.gov.py/v1/wp-content/uploads/2011/11/decreto76721. pdf> Acesso em: 10 out. 2011. 
d) Uruguai: nos 33/08, 56/08 e 57/08 sobre a modificação da Nomenclatura Comum do MERCOSUL e sua a TEC ${ }^{(47)}$; n. 50/08 que aprova o regulamento técnico do MERCOSUL para o transporte de substâncias infecciosas e amostras biológicas entre os Estados-membros ${ }^{(48)}$; n. 02/09 sobre procedimento simplificado de despacho aduaneiro no comércio intra-MERCOSUL ${ }^{(49)}$; n. 40/10 sobre a modificação da Nomenclatura Comum do MERCOSUL e sua correspondente TEC ${ }^{(50)}$.

Como resultado, tem-se que foram emitidas 71 Resoluções do GMC em 2008 e, apenas, 08 foram incorporadas pelos Estados-membros; das 41 Resoluções emitidas em 2009, apenas 04 foram incorporadas; das 58 Resoluções emitidas em 2010, apenas 18 foram incorporadas.

Sobre o cumprimento do Laudo n. 01/2008 emitido pelo TPR na controvérsia entre Uruguai e Argentina, julgada anteriormente pelo Laudo n. 1/2005 sobre a proibição imposta pela Argentina sobre a importação de pneumáticos remodelados vindos do Uruguai, no qual o TPR julgou que a Argentina deveria revogar ou modificar a Lei n. 26.329 que consta tal proibição, e determinou que, tendo decorrido o prazo de 120 dias a partir do Laudo n. 1/2005 para que a República Argentina cumprisse o referido Laudo, o Uruguai tem direito a manter as medidas compensatórias contra a Argentina até o cumprimento do referido Laudo ${ }^{(51)}$.

No que se refere às atividades de integração do Parlasul, tem-se como resultado da pesquisa de aplicação das normas ou das atividades dos órgãos mercosulinos pelos Estados-membros, os seguintes Projetos de Normas: n. 01/2010 que determina que todos os Estados-membros do bloco adotem as medidas necessárias para garantir a utilização da bandeira do MERCOSUL ${ }^{(52)}$; e n. 02/2010 que dispõe sobre a criação e organização da Corte de Justiça do MERCOSUL ${ }^{(53)}$.

Assim, tem-se que apesar da criação do MERCOSUL viabilizar aos governos a possibilidade de solução das suas necessidades econômicas e políticas, bem como a ampliação dos mercados nacionais, verifica-se que o retrato do arcabouço jurídico-normativo que se apresenta não possui uma forma unificada, comum a todos os integrantes do MERCOSUL, visto que dependa de posições domésticas sobre sua dinâmica de integração.

(47) Todas as três Resoluções pelo Decreto n. 4.06/2009 do Ministério da Economia e Finanças. Disponível em: <http://www.impo.com.uy/busqueda_resultados.html? cx=016896505430928815050\%3Al_lqxd-_ ry\&cof=FORID\%3A10\&ie=UTF-8\&q=GMC\&sa=Buscar $>$ Acesso em: 10 out. 2011.

(48) Pelo Decreto n. 392/2011: Adopta la Resolución. Disponível em: <http://www.aduanas.gub.uy/innovaportal/v/8713/1/ innova.front/decreto_n _ 392_011.html> Acesso em: 10 out. 2011.

(49) Pelo Decreto n. 232/2011. Disponível em: <http://www.aduanas.gub.uy/innovaportal/v/7839/1/innova.front/decreto_ n _232_011.html> Acesso em: 10 out. 2011.

(50) Pelo Decreto n. 2.79/2010 do Ministério de Economia e Finanças. Disponível em: <http://www.impo.com.uy/copetes/ pdf/20100317/indice.pdf> Acesso em: 10 out. 2011.

(51) Disponível em: <http://www.sice.oas.org/dispute/mercosur/laudo\%20001_008_p.pdf> Acesso em: 10 out. 2011.

(52) Disponível em: <http://www.parlamentodelmercosur.org/innovaportal/file/5352/1/proy_de_norma_01_2010_uso_ bandera_mercosur.pdf> Acesso em: 15 out. 2011.

(53) Disponível em: <http://www.parlamentodelmercosur.org/innovaportal/file/5353/1/proy_de_norma_02_1010_corte_ de_justicia.pdf > Acesso em: 15 out. 2011. 
Entretanto, ressalta-se um contraponto ante os referidos interesses internos. Assim, para que o processo de integração das normas do bloco siga em evolução, necessário se faz a atuação expressiva dos seus órgãos, principalmente, do Parlasul, pois esse possui como competência precípua agilizar os trâmites de incorporação das normas do MERCOSUL nos ordenamentos jurídicos internos de seus Estados, bem como apoiar o compromisso democrático regional. Isto porque o Parlasul representa a sociedade mercosulina, levando ao conhecimento de seus governantes o posicionamento de seus cidadãos, que possuem papel significativo nas relações que impulsionam o desenvolvimento do MERCOSUL.

\section{CONCLUSÃo}

Dentre os esforços da integração de Estados, destaca-se a institucionalização do MERCOSUL no âmbito da América do Sul. Este estabeleceu a formação de uma união aduaneira, visando o desenvolvimento da economia internacional desses países.

A criação do referido bloco representou a convergência dos interesses daqueles Estados para potencializar e reajustar suas economias internas, num primeiro momento, para que pudessem adquirir maior visibilidade nas negociações das relações internacionais mundiais.

O caráter intergovernamental do MERCOSUL limita a atuação imperativa de seus órgãos de integração regional, visto que suas normas, propostas de normas e laudos jurídicos estão sujeitos às aprovações internas dos Estados-membros e, dessa forma, percebeu-se a ausência da supranacionalidade no bloco. Entretanto, os órgãos do MERCOSUL exercem importante função para o desenvolvimento do Direito comum do bloco, pois atuam para que haja a formação de uma comunidade de Estados unidos pelo desenvolvimento da região.

Pela análise do número de incorporação das normas do bloco e cumprimento das demais determinações dos órgãos mercosulinos, percebeu-se que menos da metade foram cumpridas pelos Estados-membros o que nos faz levantar as seguintes conclusões: conforme autores ponderam, estaria o MERCOSUL "preso" aos objetivos políticos internos dos Estados; deveriam ser adotadas ações conjuntas entre os órgãos mercosulinos e os Estados-membros para acabar com o descompasso da incorporação das normas e cumprimento das determinações do Parlasul e dos Laudos do TPR; pelo caráter mercantil do bloco estaria sendo descartada a formação de um ordenamento comum aplicável a todos os Estados-membros.

Contudo, como a situação atual do MERCOSUL não é estática, em termos dos vários acordos e relações internacionais desenvolvidos intra e extrabloco, aquele pode se expandir para o alto grau de integração, tornando-se uma comunidade de Estados amparados por um Direito comum, caso haja a união política, social, econômica e cultural.

Portanto, verifica-se que, além do diálogo político, há de se fazer presente o diálogo da cooperação interparlamentar, mediante procedimento de harmonização parlamentar, sendo capaz de favorecer a instituição de normas comuns, contribuindo, assim, para que a segurança jurídica do MERCOSUL também se torne um dos princípios basilares desta integração regional de suma importância para o Brasil e seus parceiros. 
Por meio deste trabalho não se pretendeu esgotar a pesquisa que se estende sobre o tema; por outro lado, tal estudo representa uma colaboração para literatura que discute o Direito Comunitário, tão atual e instigante.

\section{REFERÊNCIAS}

ALMEIDA, Paulo Roberto. Dilemas da soberania do MERCOSUL: a soberania. Rio de Janeiro: Renovar, 1999.

ANDRADE, Mayra Thaís. S. O caráter supranacional do Conselho Mercado Comum — uma perspectiva de integração pelo Direito Comunitário. Anais do 3ํㅡㄹ Encontro Nacional da Associação Brasileira de Relações Internacionais (ABRI), USP, 2011.

ANSELMO, José Roberto. O MERCOSUL sob a ótica do direito comunitário. Revista do Instituto de Pesquisas e Estudos, Bauru, n. 29, p. 149-160, ago./nov. 2000.

BORGES, José Souto Maior. Curso de Direito Comunitário. 2. ed. São Paulo: Saraiva, 2009.

BRUM, Argemiro Jacob. O desenvolvimento econômico brasileiro. 21 ed. Petrópolis/I jui: Vozes/ UNIJUI, 2000.

CAMPOS, João Mota de; CAMPOS, João Luiz Mota de. Manual de Direito Comunitário — O Sistema Institucional. A Ordem Jurídica. O Ordenamento Económico da União Europeia. Coimbra: Coimbra, 2007.

CARNEIRO, Cynthia Soares. Para Entender o Direito da integração regional. In: BRANT, L. N. C. (Org.). Belo Horizonte: Del Rey, 2007.

CARVALHO, José Antônio Marcondes de; BENJAMIN, Daniela. Supranacionalidade ou efetividade: a dimensão jurídico-institucional do Mercosul. In: Seminário Mercosul 15 anos: Avaliação e perspectivas. São Paulo, março de 2006.

CARVALHO, Kildare Gonçalves. Direito Constitucional. Belo Horizonte: Del Rey, 2009.

COSTA E SILVA, Danielle Cristine. Soberania e MERCOSUL. Dissertação de Mestrado. Pontifícia Universidade Católica de Minas Gerais, Belo Horizonte, 2003.

EVERTS, Philip. Democracy and foreign policy. In: CASTERMAS-HOLLEMANP, Monique; HOOF, Fried Van; SMITH, Jaqueline. The role of the nation-estate in the 21st century: human rights, international organizations and foreign policy. The Hague: Cambridge, 1998.

FARIA, Adriana Spagnol de. Soberania popular e a supranacionalidade no MERCOSUL. Dissertação de Mestrado. Pontifícia Universidade Católica de Minas Gerais, Belo Horizonte, 2004.

FERREIRA, Thiago José Milet Cavalcanti. Efeito direto das normas comunitárias: Um ensaio sobre o futuro da experiência brasileira. Jus Navigandi, Teresina, ano 13, n. 2139, 10 maio 2009. Disponível em: <http://www.jusnavigandi.com.br> Acesso em: 25 ago. 2010.

GUERRA, Sidney Cesar Silva. Os desafios à integração regional no âmbito do Mercosul. Revista de Direito da UNIGRANRIO, v. 3, p. 1-26, 2009.

JO, Hee Moon. Introdução ao Direito Internacional. 2. ed. São Paulo: LTr, 2004.

MAGALHÃES, Maria Lúcia Cardoso de. A harmonização dos direitos sociais e o MERCOSUL. Revista do Tribunal Regional do Trabalho da 3를 Região — Belo Horizonte, 32 (62), p. 51-65, jul./dez.2000. 
MERCOSUL. Tratado de Montevidéu de 1980. Disponível em: <http://www2.mre.gov.br/ dai/m_87054_1980.htm> Acesso em: 02 maio 2011.

MERCOSUL. Tratado de Assunção. Assunção, 26 de março de 1991. In: MAZUOLLI, Valério de Oliveira. Coletânea de Direito Internacional. 7. ed. São Paulo:Revista dos Tribunais, 2009.

MERCOSUL. Protocolo de Ouro Preto. Ouro Preto, 17 de dezembro de 1994. In: MAZUOLLI, Valério de Oliveira. Coletânea de Direito Internacional. 7. ed. São Paulo: Revista dos Tribunais, 2009.

MERCOSUl. Disposição CPC n. 35/00. Emanada da Comissão Parlamentar Conjunta. Porto Alegre, 09 de novembro de 2000.

MERCOSUL. Protocolo de Olivos. Olivos, 18 de fevereiro de 2002. In: MAZUOLLI, Valério de Oliveira. Coletânea de Direito Internacional. 7. ed. São Paulo: Revista dos Tribunais, 2009.

PEROTTI, Alejandro Daniel. Estructura institucional y derecho en el MERCOSUR. RDIM, Buenos Aires, ed. La Ley, n. 1, p. 63-137, 2002.

RIBEIRO, ElisaS. O Parlamento do MERCOSUL como recurso para a construção do Direito Comunitário. Universitas Jus. UNICEUB, v. 16, p. 181-206, 2008.

SILVA, Renata Cristina de Oliveira Alencar; SILVA, Osvaldo Alencar. Supranacionalidade e integração: o caso MERCOSUL. Jus Navigandi, Teresina, ano 7, n. 64, abr. 2003. Disponível em: <http://jus2. uol.com.br/doutrina/texto.asp?id=3985> Acesso em: 06 set. 2010.

SILVA, Roberto Luiz. Direito Econômico Internacional e Direito Comunitário. Belo Horizonte: Del Rey, 1995.

Análise Comparativa entre o sistema processual comunitário e da integração. Scientia Iuris, Londrina, v. 4, p. 258-303, 2000.

Direito Internacional Público. 4 ed. Belo Horizonte: Del Rey, 2010.

SOARES, Mário Lúcio. Teoria geral da cidadania em suas expressões clássicas-Paradigma greco-romano e medieval. Dissertação de Mestrado. Faculdade de Direito da UFMG: Belo Horizonte, 1995, p. 5.

SOARES, Mário Lúcio. Mercosul — direitos humanos, globalização e soberania. Belo Horizonte: Inédita, 1997.

STRENGER, Rafael Dahne. Laudos arbitrais do MERCOSUL e seus princípios norteadores. Dissertação de Mestrado. Faculdade de Direito da Universidade de São Paulo, São Paulo, 2009.

TAVARES, Fernando Horta. O Direito da União Européia: Autonomia e Princípios. Virtuajus. Revista eletrônica da Faculdade Mineira de Direito, v. 2, p. 5, 2006.

VENTURA, D. F. L. Os dilemas da institucionalização: um turning point para o MERCOSUL. São Paulo em Perspectiva, São Paulo, v. 9, n. 1, p. 75-79, 1995.

VIEIRA, Luciane Klein; CHIAPPINI, Carolina Gomes. Análise do Sistema de Aplicação das normas emanadas dos Órgãos do MERCOSUL nos ordenamentos jurídicos internos dos Estados-partes. XVII Encontro Preparatório para o Congresso Nacional do CONPEDI — Salvador. Junho 2008. Disponível em: <http://www.conpedi.org.br/manaus/arquivos/anais/salvador/luciane_klein_vieira.pdf> Acesso em: 28 ago. 2010.

YUSTE, Juan Carlos. MERCOSUL social, matéria pendente. Boletim Eletrônico do Programa Mercosul social e solidário, n. 17, 28 de novembro de 2006. 